\title{
acatech Industrie 4.0 Maturity Index - A Multidimensional Maturity Model
}

\author{
Violett Zeller ${ }^{1}$, Christian Hocken ${ }^{2}$ and Volker Stich ${ }^{1}$ \\ ${ }^{1}$ Institute for Industrial Management (FIR) at RWTH Aachen University, Campus-Boulevard \\ 55, 52074 Aachen, Germany \\ 2 i4.0MC - Industrie 4.0 Maturity Center, Campus-Boulevard 55, 52074 Aachen, Germany \\ violett.zeller@fir.rwth-aachen.de
}

\begin{abstract}
Manufacturing companies worldwide recognized the high potential of Industrie 4.0 in order to increasing production efficiency. Key benefits include creation of integrated systems, networked products and improvement of service portfolios. However, for many companies deriving and evaluating necessary measures to use Industrie 4.0 potentials represents a major challenge. This paper introduces the "acatech Industrie 4.0 Maturity Index" as an approach to meet this challenge. The development of multidimensional maturity model intents to provide companies an assessment methodology. The aim is to capture the status quo in companies in order to be able to develop individual roadmaps for the successful introduction of Industrie 4.0 and manage the transformation progressively.
\end{abstract}

Keywords: Industrie 4.0, maturity model, agile company, manufacturing companies

\section{Introduction}

Production have been influenced crucially by digitalization in recent years that this progress is incomparable with any previous technical development. This process enables the initiation of the fourth industrial revolution - abbreviated by "Industrie 4.0" [1].

Concept and vision of Industrie 4.0 is often defined as "real-time, high data volume, multilateral communication and interconnectedness between cyber-physical systems and people”, in order to realize self-optimizing business processes [3]. This depiction of Industrie 4.0 does not only seem to be very complex, but concentrates also primarily on a technological understanding with the objective that manufacturing companies achieve a competitive advantage. The fundamental economic lever of Industrie 4.0 lies in stimulating business processes through necessary decisions and real-time adaptations [2]. Short decision-making processes are determined fundamentally by the huge economic disposition of data and information

Combined with adequate organizational conditions, companies are able to react faster to growing market dynamics, to develop new products more quickly and precisely in accordance with customer requirements and to launch them with a considerable lead on markets [4; 5; 9]. Therefore, an agile company is able to adapt constantly to 
changing conditions using suitable technologies and organizational learning as well as is capable of permanently occupying digital control points.

In cooperation with research institutes, industrial partners and the acatech - the national academy of science and engineering - the "acatech Industrie 4.0 Maturity Index" was designed to support manufacturing companies to identify individual, customized recommendations for action in order to realize the transformation [3].

\section{Methodology of the acatech Industrie 4.0 Maturity Index}

The main difference between the approach presented here and other maturity models or indexes is a holistic view and the direct correlation to the company goals. The model's approach is based on a succession of maturity levels, i.e. value-based development stages (see section 2.2.1) that help companies navigate their way through every stage in the digital transformation, from the basic requirements for Industrie 4.0 to full implementation. Since a company desired target state will depend on its business strategy, it is up to each company to decide which maturity level represents the best balance between costs, capabilities and benefits for its own individual circumstances, taking account of how these requirements change over time in response to changes in the business environment and the company's strategy. To ensure that all aspects of manufacturing companies are taken into account, the model's structure is based on the "Production and Management Framework” by [6]. The framework's four structural areas enable a comprehensive analysis and set out a number of guiding principles.

In the following, the underlying model of the acatech Industrie 4.0 Maturity Index is illustrated. First, the stages of development, which describe capabilities of a company in order to achieve the full potential of Industrie 4.0, are explained. Then, section 2.2.2. considers the four structural areas of resources, information systems, culture and organizational structure, which are vital to be considered for the transformation into a learning, agile company. Afterwards the model's application in a manufacturing company is exemplified in section 3.

\subsubsection{Value-based Development Stages - Industrie 4.0 Maturity Levels}

The basic structuring of Industrie 4.0 into successive stages presented below in Fig. 2.1 to provide manufacturing companies an overview of the required activities for digitalization. The subdivision and explanation of the individual stages as well as the necessary measures serve as support so that companies can better place the impending change in their own company context.

The development path is based on computerization (1), which is the starting point for digitization and refers to the targeted use of information technologies. In most companies, the computerization stage is largely in a highly advanced state and is particularly used for the efficient design of repetitive activities, as it enables cost-effective production with low error rates and generates the necessary precision, which is indispensable for the production of many modern products [3; 9]. Achieving the connectivity level (2), the targeted or isolated use of IT is replaced by networked components, whereby IT systems are interconnected and represent a projection of the corporate core business 
processes. A complete integration between IT (information technologies) and OT (operative technologies) levels has not yet taken place; however, interfaces to business IT are provided by parts of implemented OT [3; 11; 12].

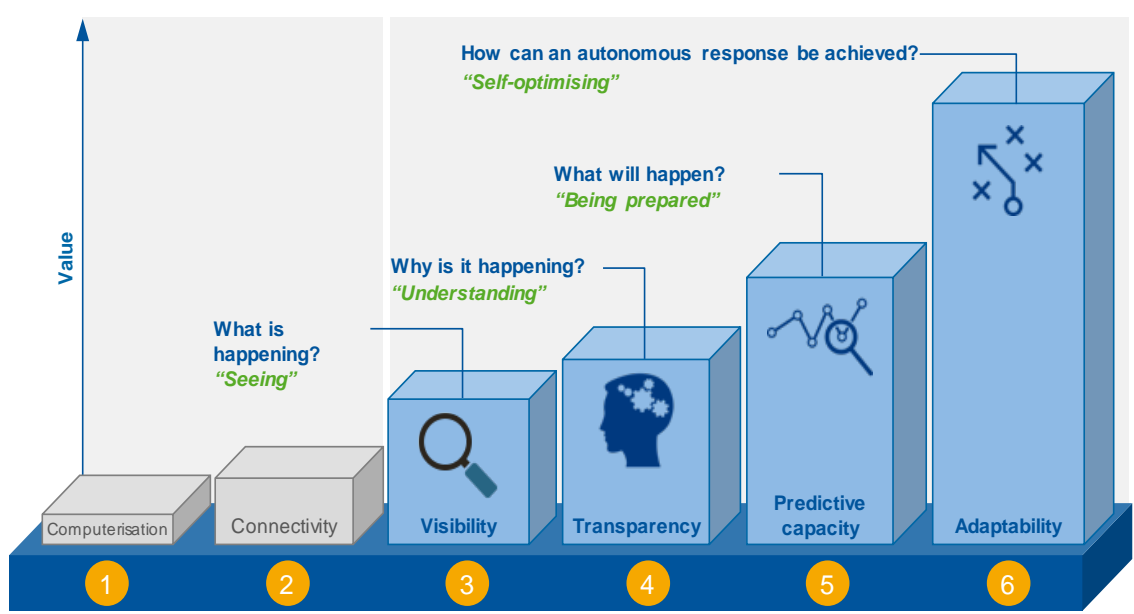

Fig. 2.1 Value-based development stages of Industrie 4.0 - Industrie 4.0 Maturity Levels [3]

Based on this, a digital visibility (3) is established with the help of sensors, which enable recording of processes from start to finish with a high amount of captured data. Processes states are no longer limited to individual areas, such as in a production cell, but can be extended to a production system or the entire company in real time in order to create a digital model, also known as the "digital shadow" [7]. This digital shadow, which is to be understood as a basic element for the subsequent maturity levels, helps to show what is happening in the company (real time) and enables data-based decisionmaking in management [3; 7; 9]. For a better causal understanding of processes, it is necessary to create further transparency (4) about the correlations in data stocks. The recognition and interpretation of interdependencies through the digital shadow requires the analysis of the collected data in the respective context using engineering knowledge. Process knowledge is more and more required to support more complex decisions, which are based on semantic connections and aggregation of data and its corresponding classification in a certain context. This process is supported fundamentally by new technologies for the analysis of mass data. Building up, the predictive capability level (5) enables simulation of different future scenarios and identification of those that are most likely. To this end, the digital shadow is projected into future-based scenarios and evaluated according to probability of occurrence. This enables companies to anticipate upcoming events, make decisions in time and take adequate reaction measures. Although measures usually still have to be initiated manually, the effects of a disruption can be limited in time due to the time gained through the prewarning. Reducing such disruptions or planning variance, which represent unexpected events in the business process, enables more robust operation. The ability to adapt (6) can enable an automatic reaction to expected machine failures or delays in delivery through a modified sequence in production planning. If a company manages to exploit data of the digital shadow in such a 
way that decisions are made autonomously, with the best positive results in the shortest possible time and the corresponding measures are taken, then stage six of the model has been successfully implemented [5]. It is, however, important to assess carefully the risks of automating approvals. For this a correct cost-benefit ratio must be given.

\subsubsection{Required Capabilities for a Company's Structural Areas}

The skills that are relevant for the transformation of a manufacturing company into a learning, agile organization are assessed through the four structural areas of resources, information systems, culture and organizational structure (see Fig. 2.2). All of them characterize the structure of an organization and are examined over six levels of Industrie 4.0 development path, which is represented by six concentric circles in Fig. 2.2.

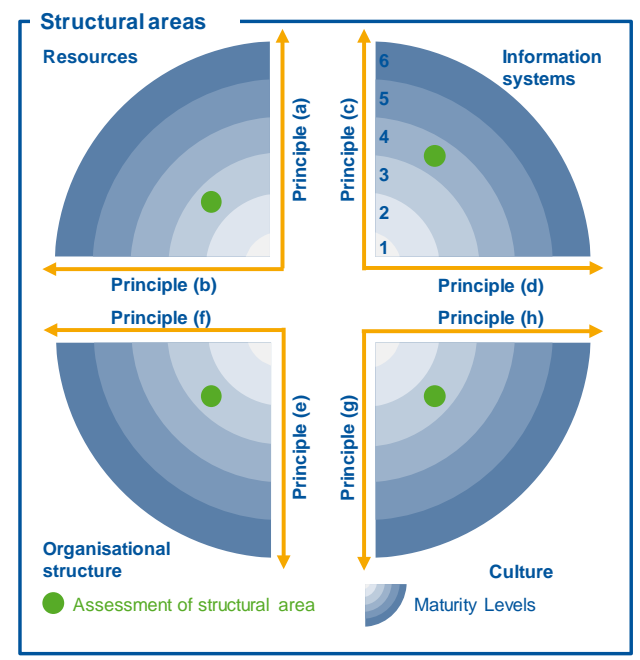

Fig. 2.2 Structure of the structural areas [3]

Each structural area is divided by two principles, each of which - depending on the benefit-oriented development levels - successively builds up skills. These skills guide the further development of the manufacturing company. The degree to which the abilities are implemented determines the maturity level of each principle. The maturity levels of the two principles are summarized and together they represent the evaluation of the structural area, which is oriented on the development levels.

The structural area resources includes all physical, tangible resources. This contains, for example, employees of a company, machinery and systems, the tools and materials used and the final product. The aim is to design resources that enable an interface between the physical and digital worlds in addition to pure functional fulfilment, thereby creating a digital shadow that forms the basis of the learning process for optimizing agility.

The two principles dividing this structural area are differentiated into digital competence and structured communication. "Digital competence" (a) characterizes the gen- 
eration of data and its target-oriented independent processing into information by resources with corresponding technical components. This facilitates an informationdriven way of working, based on feedback from the process environments and not on forecast-based planning specifications. The skills of digital competence also include the use of embedded systems and the retention of digital competence, which can only be successful, if attention is paid to promoting interdisciplinary thinking and action by employees - if they are increasingly integrated into the innovation process. Through "structured communication" (b) collected information is linked and creates an overall picture. An efficient communication can be defined and interface designed in order to support decision-makers. [3; 7; 8]

With the help of employees, information technologies and data information is available within information systems in accordance to economic criteria. Many manufacturing companies do not make sufficient use of data. The decisive factor is the insufficient processing of the collected data into information and its subsequent provision to the employees, which is why the first principle includes the processing and preparation of data (c) for decision support. This requires, among other things, context-based information provision, data storage and application-oriented interfaces in order to provide a technical infrastructure for real-time use of data and information ultimately [10]. In the context of the second principle, it is a question of integration for optimized data (d) use and increased agility under the primary aspect of data sharing within the value chain.

The transformation to a learning, agile company is achieved through the technologies explained above and the implementation of an appropriate organizational structure. In this model, the organizational structure refers on the one hand to the internal corporate organization (e) in the form of organizational structures and processes, and on the other hand describes the positioning in the value network (f). In contrast to the structural area culture described below, the organizational structure establishes mandatory rules that organize collaboration both within the company and externally. A high degree of individual responsibility on the part of employees is characteristic of the organic internal organization, which is why a highly skilled workforce is of fundamental importance for such an organizational form. Especially the so-called "flexible communities", i.e. the fast formation of organizational units to solve a specific task, represent an important capability of agile organizations. In addition, the bundling of the high degree of personal responsibility through motivating target systems and their orientation towards customer benefit is important, which is particularly feasible through agile management. Whether a company is in a position to cooperate within networks can be determined by, among other things, achieving shorter reaction times to changing market requirements by bundling competencies in line with demand [3].

A company's agility is highly dependent on the behaviour of its employees. Companies will be unable to achieve the desired agility if they simply introduce digital technologies without also addressing their corporate culture. In this context, two directions for changing corporate culture can be mentioned: willingness to change $(g)$ and social collaboration ( $h$ ). The first term refers to the willingness of employees to continuously analyze and, if necessary, adapt their own behavior. This willingness to adapt within the framework of readiness for change goes along with the prerequisite of being able to recognize opportunities for change and then initiate appropriate measures. In addition, 
it is advantageous to see mistakes not as a problem, but as a treasure or as an opportunity for positive change and a certain openness for innovations as well as a willingness to undergo continuous further training. The term social collaboration refers to the consideration of knowledge as a decisive guideline for action, which implies that an ideal state is characterized by making decisions based on knowledge [8].

For each structural area, specific Industrie 4.0 skills must be achieved with regard to the development stages. In this regard, a holistic assessment for manufacturing companies is realized.

\section{$3 \quad$ Application of the acatech Industrie 4.0 Maturity Index}

The application of the acatech Industrie 4.0 Maturity Index consists of three successive phases (see Fig. 3.1) [3]. The first phase serves to determine the current maturity stage of the company, for which an examination of the existing Industrie 4.0 capabilities conducted according to the considered business process (e.g. production, logistics, service) and structural areas. The second phase aims - and based on the corporate strategy - to determine the target development stage with a view to the subsequent transformation process. A gap analysis helps to identify the missing required capabilities that still need to develop. These will depend on the current development stage ascertained in phase 1 and the target state that the company wishes to achieve by the end of the transformation. Finally, the derivation of appropriate measures and incorporating them into a roadmap for the development of the identified capabilities in the third phase takes place.

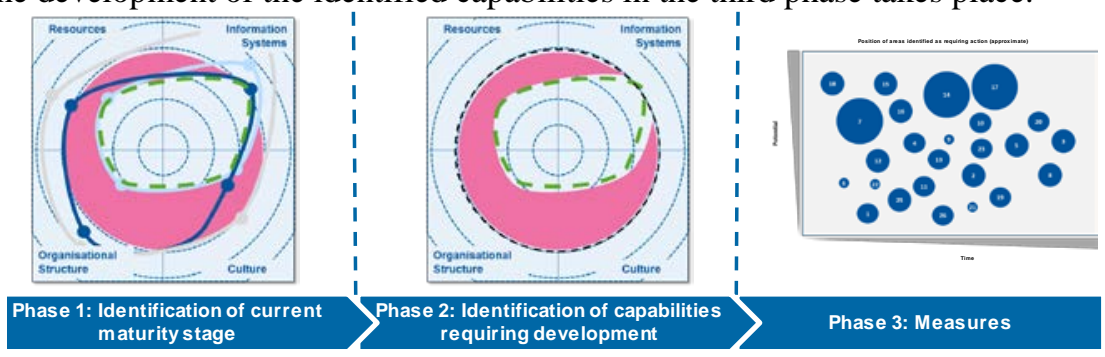

Fig. 3. 1 Application of the acatech Industrie 4.0 Maturity Index [3]

\subsection{Phase 1: Identifying the current Industrie 4.0 development stage}

The company's location results from the six value-based development stages for Industrie 4.0 (see Section 2.1.1.) and the skills dedicated to them. For an appropriate assessment, the consortium has developed a questionnaire, with approx. 600 questions for the business processes engineering, production, logistics, service, sales and marketing. An inspection of a production plant can give a first impression of the processes, followed by a detailed evaluation of the business processes. The as-is analysis and the questionnaire is conducted based on the order processing process, which forms the framework situation for the evaluation of existing skills. With the help of a questionnaire evaluation the Industrie 4.0 Maturity Index and Levels can be identified for each structural area. 


\subsection{Phase 2: Capabilities to be acquired}

For the evaluation, the answers to the questionnaire shape the basis for the evaluation of the current situation of the company by the radar image (see Fig. 3.1). This display can be used to make quick statements about the average level of maturity and to clarify inconsistencies with regard to the characteristics of the four structural areas. The dependencies of the structural areas determine consistent development in all structural areas as an essential goal. This is the basis for the recommendation for companies to approach the resulting areas of action and to strive for a consistent maturity stage across all four structural areas and in this way to use the maturity stage (achieve maturity stage consistency). With regard to some areas, such as complex logistical processes, whose effectiveness is particularly determined by organizational performance. There may be some operating areas or functions where the majority of the available benefits are achieved without the requirement for balance and equal levels of maturity among the four structural areas [3].

\subsection{Phase 3: Identifying concrete measures}

The next step is to derive measures addressing areas identified as requiring action. Necessary measures can be deduced from the missing capabilities evaluating the four structural areas. By evaluating individual processes, many individual measures can be dedicated, which makes it easier for companies to create a digital roadmap.

In defining strategic objectives for a company, identified measures are worked out precisely. Achieving the targeted stages of development, in turn, aims to support the realization of the strategic objectives formulated at the outset. This enables decision-makers in manufacturing companies not only to identify at a glance the measures needed to achieve a higher maturity level, but also the interdependencies between identified measures. The purpose of this presentation is also to simplify the creation of a digitization roadmap by determining the order in which measures are implemented in terms of time and costs [3].

To date, the Maturity Index has been applied in 26 companies and their plants. The effort is essentially still very high (3-day workshop at the plant and 3-5 days evaluation). however, the organizations receive individual industry 4.0 roadmaps with many measures that help to reach the next level of maturity in all dimensions.

\section{Conclusion and Outlook}

In the context of Industrie 4.0, agile action and real-time changes become a company's strategic success factor. The acatech Industrie 4.0 Maturity Index provides companies a supporting tool for transformation into a learning, agile company. It describes six benefit-oriented development stages for four key areas of each company, each of which delivers additional benefits to the company. This approach can be used to develop a digital roadmap precisely tailored to the needs of each individual company in order to help them master the digital transformation across all involved relevant business units. In addition, the findings and the model can be used to developed tools and best practices 
that assist companies with the concrete shaping of the transformation. In this context, this specific procedure should be developed for different industrial sectors so that recommendations can be made as precisely as possible and to reflect the differences between individual industries.

The model developed is based on the principle of continuous learning and requires additional information resulting not only from validations but also from interaction and exchange with interested industrial and research partners [9].

\section{References}

1. Schuh, G.; Jordan, F.; Maasem, C.; Zeller, V.: Industrie 4.0: Implikationen für produzierende Unternehmen. In: Digitale Transformation im Unternehmen gestalten. Geschäftsmodelle, Erfolgsfaktoren, Handlungsanweisungen, Fallstudien. Hrsg.: O. Gassmann; P. Sutter. Hanser, München 2016, p. 39-58

2. Schmitz, S.; Wenger, L.: Acatech Industrie 4.0 Maturity Index: Welche Fähigkeiten sind im Wandel entscheidend? In: IT\&Production (2017b) 5, S. 54 - 55.

3. Schuh, G., Anderl, R., Gausemeier J., ten Hompel, M., Wahlster, W. (Eds.): Industrie 4.0 Maturity Index. Managing the Digital Transformation of Companies (acatech STUDY), Munich: Herbert Utz Verlag 2017, p. 21

4. Infosys (2015): Industry 4.0. The state of the nations. 1. Aufl. Hg. v. Infosys Ltd. Bangalore, Indien.

5. McKinsey (2015): Industry 4.0. How to navigate digitalization of the manufacturing sector. Unter Mitarbeit von Dominik Wee, Richard Kelly, Jamie Cattel und Matthias Breunig. Hg. v. McKinsey

6. Boos, W./Völker, M./Schuh, G.: „Grundlagen des Managements produzierender Unternehmen“. In: Schuh, G./Kampker, A. (Hrsg.): Strategie und Management produzierender Unternehmen. Handbuch Produktion und Management 1, Berlin, Heidelberg: Springer Verlag (VDI-Buch) 2011, S. 1-62.

7. Bauernhansl, Thomas; Krüger, Jörg; Reinhart, Gunther; Schuh, Günther: WGP-Standpunkt Industrie 4.0. Hg. v. Wissenschaftliche Gesellschaft für Produktionstechnik Wgp e. V.

8. Zühlke, Detlef (2013): Die Cloud ist Voraussetzung für Industrie 4.0. Präsentation. VDI. VDI-Pressegespräch anlässlich des Kongresses „AUTOMATION 2013“. Baden-Baden, 6/25/2013

9. Schuh, G.; Potente, T.; Thomas, C.; Hauptvogel, A. (2014): Steigerung der Kollaborationsproduktivität durch cyber-physische Systeme. In: Thomas Bauernhansl, Michael ten Hompel und Birgit Vogel-Heuser (Hg.): Industrie 4.0 in Produktion, Automatisierung und Logistik. Wiesbaden: Springer Fachmedien Wiesbaden, S. 277-296.

10. Hering, Niklas; Brandenburg, Ulrich; Frey, Dominik; Ihne, Manfred; Meißner, Jan; Reschke, Jan; Schenk, Michael (2015): Smart Operations. Hg. v. FIR an der RWTH Aachen. Aachen.

11. Vogel-Heuser, Birgit (2014): Herausforderungen und Anforderungen aus Sicht der IT und der Automatisierungstechnik. In: Thomas Bauernhansl, Michael ten Hompel und Birgit Vogel-Heuser (Hg.): Industrie 4.0 in Produktion, Automatisierung und Logistik. Wiesbaden: Springer Fachmedien Wiesbaden, S. 37-48.

12. Kaufmann, Thomas; Forstner, Lisa (2014): Die horinzontale Integration der Wertschöpfungskette in der Halbleiterindustrie. Chancen und Herausforderungen. In: Thomas Bauernhansl, Michael ten Hompel und Birgit Vogel-Heuser (Hg.): Industrie 4.0 in Produktion, Automatisierung und Logistik. Wiesbaden: Springer Fachmedien Wiesbaden, S. 359-367. 